\title{
LA LITERATURA MARGINAL PERIFÉRICA Y EL SILENCIO DE LA CRÍTICA
}

\author{
Julio Souto Salom \\ Universidade Federal do Rio Grande do Sul \\ juliosouto2103@gmail.com
}

RESUMEN / RESUMO / ABSTRACT

Revisamos la recepción de la literatura marginal periférica en el campo literario brasileño. Este movimiento literario, nacido con el cambio de siglo, se distingue por ser producido por sujetos identificados con espacios de exclusión social, como periferias, favelas o presidios. En un primer momento, algunas obras de este tipo fueron acogidas con sorpresa, celebrando lo que era considerado un "descubrimiento insólito". Se enfatizó principalmente su "mirada interna" sobre estos universos, con obras que proponen "pactos de lectura múltiples" combinando lo novelesco, lo testimonial y lo autobiográfico. Sin embargo, esta consideración no hace justicia a la riqueza y diversidad de este movimiento, que con la proliferación de saraus en las periferias de São Paulo, viene constituyendo un "sistema literario" independiente, marcado por la oralidad y la dimensión performática de lo literario. Ante este nuevo escenario, la crítica hegemónica permanece sorda.

PALABRAS CLAVE: literatura marginal periférica, campo literario brasileño, saraus periféricos, crítica literaria.

Revisamos a recepção da literatura marginal periférica no campo literário brasileiro. Este movimento literário, nascido na virada do século, se distingue por ser produzida por sujeitos identificados com espaços de exclusão social, como periferias, favelas ou presídios. Em um primeiro momento, algumas obras deste tipo foram acolhidas com surpresa, celebrando o que era considerado uma "descoberta insólita". Enfatizou-se principalmente o seu "olhar interno" sobre estes universos, com obras que propõem "pactos de leitura múltipla" combinando o romanesco, o testemunhal, e o autobiográfico. Porém, esta consideração não faz jus à riqueza e diversidade desse movimento, que com a proliferação dos saraus nas periferias de São Paulo, vem construindo um "sistema literário" independente, marcado pela oralidade e a dimensão performática do literário. Ante este novo cenário, a crítica hegemônica permanece surda. 
PALAVRAS-CHAVE: literatura marginal periférica, campo literário brasileiro, saraus periféricos, crítica literária.

We review the reception of Peripheral Marginal Literature in the Brazilian literary field. This literary movement, born at the turn of the century, is produced by subjects identified with spaces of social exclusion, such as urban peripheries, favelas, or prisons. At first, some works of this kind were received with surprise, celebrating what was considered to be an "unusual discovery". There was usually an emphasis on its "internal view" of these universes, with books that propose "multiple reading pacts", combining the novelistic, the testimonial, and the auto-biographical. However, this consideration does no justice to the wealth and diversity of this movement which, with the proliferation of saraus on the peripheries of São Paulo, is forming an independent "literary system" marked by orality and the performative dimension of literature. In this new scenario, hegemonic criticism remains deaf.

KEYWORDS: Peripheral Marginal Literature, Brazilian literary field, peripheral saraus, literary criticism.

\section{LA NUEVA LITERATURA BRASILEÑA: ¿“BLANCA, URBANA Y DE CLASE MEDIA"?}

Un significativo artículo del diario El País - Edición Brasil, presenta el siguiente titular: "A nova literatura brasileira: Jovem, branca, urbana e de classe média" (Ballesteros, 2014). Con estos rasgos sociales esenciales, la periodista pretende caracterizar "a última geração de escritores brasileiros, [que] se distancia do exotismo e cultiva uma narrativa cosmopolita e global". En el mismo artículo se incluyen declaraciones de algunos de estos escritores, como las de Carola Saavedra, que comenta

Estamos em um momento ótimo. Não porque a literatura está melhor agora que há 20 anos, mas porque é uma época bastante favorável para os autores, publica-se mais e inclusive há incentivos para traduções. No entanto, devemos lidar com um problema muito sério que é a falta de leitores. E para isso, seria urgente uma mudança em todo o sistema educacional do país (Saavedra, cit. en Ballesteros).

Parece paradójico el escenario literario descrito por esta escritora (efectivamente joven, blanca, urbana y de clase media), donde se aprecia una relativa expansión de la industria editorial ("ahora se publica más"), apoyada por políticas públicas fuertes orientadas a difundir internacionalmente la literatura brasileña ("incluso hay incentivos para traducciones"), pero al mismo tiempo se muestra malestar por un déficit de lectores dentro del propio país ("un 
problema muy serio"). Y a tal diagnóstico, tal propuesta: "sería urgente un cambio en el sistema educativo del país". Esto es, la propuesta política de Carola Saavedra planteada en el artículo de El País, que de cierta forma refleja el pensamiento dominante en los medios intelectuales y académicos, pasaría por implementar políticas públicas en el área cultural y educativa, con el objetivo de formar prácticas, gustos y preferencias culturales, para que la población brasileña (en gran parte negra o mestiza, periférica o rural, mayoritariamente de clase trabajadora) consuma esa literatura "blanca, urbana y de clase media".

Aunque pueda parecer contradictorio, ese análisis del campo literario y su consecuente desarrollo propositivo tiene como base una percepción más profunda y antigua, que presenta la literatura (en su relación con el libro, tanto en la lectura como en la escritura) como una de las prácticas culturales más elitistas de Brasil. El crítico carioca Silviano Santiago sintetizaba esta constatación ya a finales de los años ochenta:

O público de ficção no Brasil vive na grande cidade e é formado por camadas mais ou menos pervisíveis e semelhantes de leitores, reproduzindo-se identicamente de Estado para Estado. [...] Todos esses leitores [...] vivem dentro do bem-estar, do lazer e das comodidades educacionais inerentes à classe média, classe esta privilegiada por todos os milagres brasileiros desde os anos 30 , tanto os econômicos e sociais quanto os culturais. O livro é, pois, objeto de classe no Brasil e, incorporado a uma rica biblioteca particular e individual, é signo de certo status social. Como tal, dirige-se a uma determinada e mesma classe, esperando dela o seu aplauso e a sua significação mais profunda que é dada pela leitura, leitura que se torna um eco simpático de (auto)revelação e de (auto)conhecimento (Santiago 26-28).

Como está implícito en el fragmento citado, la concepción de la literatura presentada aquí es la que se organiza en torno del objeto libro, esto es, asociada a prácticas de lectura y escritura. Constatado esto, el afán de combatir el analfabetismo y formar un público lector en el país ya ha venido generando históricamente acciones culturales y educativas. De forma paradigmática, todo el proyecto literario y editorial de Monteiro Lobato en la primera mitad del siglo XX se construyó en torno a este objetivo, renovando la escritura tanto en temas como en técnicas literarias, y modificando sustancialmente las bases de producción y distribución del libro en Brasil (Passiani). Una 
primera inquietud podría planteársele aquí al sociólogo ingenuo: ¿por qué tanto interés en fomentar la literatura? O mejor, ¿por qué el Estado debería tener un compromiso con cierto tipo de literatura?

Junto a esta primera ruptura con lo aparentemente evidente, podemos intentar una recuperación de lo normalmente olvidado. Al lado de la literatura brasileña canónica, existe todo un universo de prácticas literarias que se articulan más allá del libro y de la escritura, como muestra la riquísima diversidad cultural brasileña. Estas prácticas y manifestaciones incluirían desde la poesía repentista y la literatura de cordel, pasando por el arte de los griots afrodescendientes o las narrativas orales recogidas por folcloristas, hasta géneros periurbanos contemporáneos como el rap. Si bien ciertas políticas públicas del ámbito cultural parecen abrirse a esta diversidad, por lo general estas manifestaciones permanecen históricamente excluidas del ámbito académico y los currículos escolares. ¿Por qué este desdén para este tipo de prácticas literarias? ¿Por qué el Estado brasileño, siguiendo la propuesta de Carola Saavedra, debería "modificar todo el sistema educativo del país" para crear hábitos culturales previamente inexistentes en la población, en lugar de valorizar los que ya están presentes?

La respuesta a unas y otras preguntas podría pasar por los mecanismos de creación, distribución y reconocimiento del valor literario de ciertas obras y producciones, siendo otras despreciadas, cuando no desconsiderado su estatuto literario. Retomando el mundo literario oral y popular, podemos constatar cómo este siempre estuvo asociado a las clases dominadas, lo que necesariamente los configuraba en contextos de desigualdad simbólica establecidos entre las diferentes manifestaciones y sus respectivos practicantes. Pero esto no implica que la oralidad haya vivido necesariamente de espaldas a lectura y escritura, sino que articula con estas prácticas relaciones complejas, tensas hibridaciones. Considerando que en el Brasil actual la lectura/escritura se configura como una práctica cultural dominante, las relaciones que las clases dominadas podrían establecer con ellas irían desde el rechazo y la negación de la práctica elitista, hasta las apropiaciones paródicas o subversivas.

Es en este contexto de diversidad cultural (de prácticas y manifestaciones) y desigualdad simbólica (entre clases sociales) que pretendemos comprender el reciente fenómeno de la literatura marginal periférica, surgido en Brasil en la primera década del presente siglo. 


\section{¿QUÉ MARGINALIDAD ES ESA?}

Al hablar de literatura marginal periférica estamos suscribiendo la opción terminológica de Érica Peçanha do Nascimento (É tudo nosso!) y Mario Augusto Medeiros da Silva, escogiendo una nomenclatura doble como reflejo de debates trabados entre los escritores que integran el movimiento ${ }^{1}$. Los propios escritores presentan opciones diferentes en torno de estas denominaciones colectivas, donde hay partidarios de la utilización del término "Literatura periférica" (Sérgio Vaz, el sarau de la Cooperifa), y otros de "Literatura marginal" (las coetáneas coordinadas por el escritor Ferréz), a las que todavía se podrían añadir otros términos que circulan entre escritores y críticos: "Literatura hip-hop", "Literatura suburbana", "Litera-rua", o "Literatura divergente".

Pero si asumimos la noción de "marginalidad literaria", es necesaria una mínima caracterización de este concepto, terriblemente polisémico y ampliamente utilizado con peligrosa ambigüedad. Para esto, coincidiendo con la lectura de Patrocínio (Escritos 3-4) y Nascimento (Vozes 36-37), considero que nos resulta de mucha utilidad un breve ensayo de Sérgius Gonzaga, donde la noción de marginalidad literaria hace referencia a tres ámbitos:

- Los marginales de la edición, esto es, que se sirven de tecnologías de publicación al margen de los circuitos librescos convencionales, produciendo obras mimeografiadas, fanzines, folletos fotocopiados, etc.

- Los marginales del lenguaje, que rechazarían lo que se entiende por un "lenguaje oficial", y estaría vinculado a movimientos literarios de vanguardia. En este sentido, toda producción literaria renovadora,

\footnotetext{
“A partir dos debates gerados pelas revistas, percebi que Ferréz era o grande ideólogo e defensor do uso da expressão literatura marginal para caracterizar a produção literária daqueles que vivenciaram alguma situação de marginalidade social, em particular, dos moradores da periferia. Muitos dos participantes preferiam a expressão literatura periférica, a fim de evitar o outro sentido do próprio termo marginal, que reporta aos indivíduos em condição de marginalidade em relação à lei, ou mesmo para ressaltar o lugar de onde e em nome do qual falam. Mas tanto aqueles que mantêm predileção pela expressão literatura marginal, quanto os que optam por utilizar a designação literatura periférica, assumem esses termos como uma das possibilidades de classificação de sua condição de autor ou de sua produção, e recorrem a elas, notadamente, como vetor das suas carreiras: para atender a uma demanda do mercado editorial e se aproximar do público que compartilha o mesmo perfil sociológico" (Nascimento 2012, p. 103).
} 
por más consagrada que pudiera estar hoy, comenzó siendo una "literatura marginal".

- Los marginales que representan el habla de los excluidos. Esto haría referencia a la selección de perspectivas, personajes y temas relacionados con el universo de la "marginalidad social": miseria, prostitución, crimen, etc.

El grupo literario asociado al término "poesía marginal", actuante principalmente en la década de 1970 en el escenario literario brasileño (Francisco Alvim, Zuca Sardan, Chacal, Cacaso, Waly Salomão, Nicolas Behr...), se situaría entre los dos primeros ámbitos, por su relativa renovación lingüística de las técnicas poéticas, y por el uso del mimeógrafo para difundir sus obras de forma independiente (por lo que el grupo también fue conocido como "generación mimeógrafo"). En el último ámbito, Gonzaga situaría a ciertos escritores, con João Antônio como principal representante en la literatura brasileña de su tiempo, que se preocupan por representar un universo social reprimido e invisibilizado. Sin embargo, considerando el origen y situación social de todos estos escritores, Gonzaga concluye que "os legítimos marginais, na acepção repressiva ou na acepção histórica, continuam fora do processo de fatura artística de orden letrada" (Gonzaga 148). Ante esta afirmación, Gonzaga puntualiza la única excepción posible de Plínio Marcos. Resulta extraño que un crítico brasileño como Gonzaga, ocupándose de este tema, no mencione el caso de Carolina de Jesús, cuyo Quarto de Despejo. Diário de uma favelada (1963) se convirtió en best seller internacional, narrando desde la experiencia la cotidianeidad de la exclusión social más violenta. Podemos pensar que el fuerte componente testimonial de esta obra lleva al crítico a negarle el carácter literario, dejando por tanto a Carolina de Jesús "fuera del proceso de factura artística de orden letrada". Este tipo de recepción crítica es explícita en el ensayo de Carlos Vogt, donde se argumenta que los mismos mecanismos sociales que crearon el éxito comercial de Quarto de Despejo (el interés periodístico o antropológico del texto) son los que devolvieron a la miseria a su autora (que no llegó a tener una trayectoria de consagración como escritora). A esto debemos añadir la relación de Carolina de Jesús con su "descubridor", el periodista Audalio Dantas, que compiló, editó y publicó sus diarios, provocando que desconfiados críticos y lectores iniciaran un mezquino y estéril debate sobre la autoría real de los textos. Para Silva, y coincidimos con él en lo esencial, ese desprecio a la escritura de De Jesús no responde a motivos lingüísticos sino sociológicos. Cargada de 
prejuicios, la crítica se limita a reconocer el interés sociológico de los diarios o, cuando hay cierta empatía, la carga dramática del "testimonio humano". Así, no se reconoce la intencionalidad creativa que articula sus diarios, por lo que tienen de elaboración a posteriori de la memoria inmediata, en base a la ficcionalización de lo cotidiano.

Ao contrário, atribui-se-lhe, quando se considera ser ela a autora dos diários, a espontaneidade despretensiosa. Para dizer o mínimo, esta ideia é carregada de preconceito, contendo nas entrelinhas a sugestão de que pobres e favelados (o povo, o quarto estado se estivéssemos em França) não sabem o que fazem quando escrevem, necessitando da tutela ou de alguém que lhes aponte uma direção, que fale por si. Algo semelhante acontecerá com Paulo Lins e Ferréz (Silva 245).

Perpendicularmente a este caso, es curiosa la apreciación que se hace en el mismo ensayo de Gonzaga para el caso del ya citado João Antônio, que nos lleva al extremo contrario para sostener la misma idea. En este caso, lo que se coloca en cuestión no es el carácter literario de los textos del consagrado escritor, sino precisamente la condición "marginal" de su productor. La biografía de João Antônio es adjetivada como "semi-marginal", a lo que se añade "certo apelo publicitário" (Gonzaga 151). De esta forma, los prejuicios de los que hablaba Silva en la cita anterior muestran su cara inversa: si es imposible para un "marginal" hacer "literatura", cuando de hecho hay "literatura", el autor no puede ser "marginal".

Contra ese prejuicio se erige todo el proyecto político y literario de la actual literatura marginal periférica. Combinando la presentación biográfica de los autores -que explicita su posición periférica en el espacio social-con su incontestable producción literaria, estos autores impugnan el pensamiento académico dominante que trasluce en el ensayo de Gonzaga, según el cual existiría una incompatibilidad insuperable entre la actividad literaria y la condición social excluida o, más claramente, entre las identidades "escritor" y "marginal". En este sentido, es interesante detenerse momentáneamente en ciertos abordajes de la sociología de la literatura, que nos permiten examinar con más detalle esta aparente contradicción. 


\section{APORTES DE LA SOCIOLOGÍA DE LA LITERATURA: LUCHAS DE DEFINICIÓN Y EL PROBLEMA DEL VALOR}

Una importante innovación de la sociología de la literatura de Pierre Bourdieu es la relativización del "valor literario", considerando éste no como un atributo "esencial", intrínseco a las obras, sino como un "efecto del campo" resultante de las diferentes disputas libradas en su interior ${ }^{2}$. En estos embates, los agentes implicados son múltiples, e irían desde los propios escritores, a los periodistas culturales o los críticos literarios, que juegan un papel no solo interpretativo sino performático, es decir, "a la vez que juzgan e interpretan la valía de las obras y corrientes artísticas, cumplen un papel fundamental en las luchas por la prescripción de lo que Bourdieu denomina el 'nomos' fundamental del campo: las reglas básicas de la acción en el campo" (Romero y Santoro 208). Pero incluso antes de estas luchas por establecer los diferentes valores de las obras literarias hay una fase previa de "luchas de definición", en la que esos mismos agentes determinarían, de forma inestable y nunca definitiva, qué es literatura y qué no lo es.

Si bien este modelo teórico nos permite pensar las disputas simbólicas trabadas en torno a la naturaleza y el valor literario de las diferentes obras, al mismo tiempo aparecen algunos efectos perversos que deben ser observados. El principal problema que se nos presenta, a la hora de pensar la literatura marginal periférica desde el modelo de Bourdieu, es la ubicación de estos escritores en el "campo literario" que por la arquitectura conceptual del sociólogo se constituiría como intrínsecamente dependiente del "campo del poder". En sus estudios sobre "la conquista de la autonomía" del "campo literario", Bourdieu propone una visión altamente institucionalizada y estabilizada de este espacio de relaciones, donde los agentes organizan la totalidad de sus acciones para la disputa de un capital específico (el "capital simbólico", el reconocimiento de sus pares) adoptando un habitus específico (el habitus de escritor). Desde este punto de vista, la comprensión de los autores de literatura marginal periférica estaría condenada a incurrir en la miopía teórica que observamos en Gonzaga: o bien las producciones textuales de los sujetos subalternos serían simples manifestaciones de escritura exteriores al campo

2 En otro artículo (Souto 50-53) me he dedicado con más especificidad al abordaje sociológico del problema del "valor literario" a partir de la discusión de los modelos teóricos de Pierre Bourdieu y Bernard Lahire. 
literario, esto es, sin condición literaria; o bien las obras literarias habrían sido producidas por escritores en el campo del poder, y la explicitación de su origen subalterno no sería más que un envite estratégico capitalizable en el campo literario. ¿Cómo podríamos pensar las relaciones y disputas trabadas por estos escritores en su actividad literaria (con lectores, otros escritores, periodistas, críticos, editores, etc.), sin por ello descaracterizar otros procesos de identificación social, por los que ellos mismos se posicionan en las periferias urbanas, como integrantes de los grupos sociales oprimidos que representan literariamente?

Consideramos que las constataciones empíricas que nos aportan los escritores de la literatura marginal periférica nos obligan a repensar ciertos postulados teóricos del modelo bourdieusiano, en lo relativo a la presuposición de la coherencia interna del habitus para las prácticas y preferencias culturales de sujetos o grupos sociales homogéneos; y específicamente al hablar de literatura, en lo relativo a la delimitación y estabilidad del campo literario, como un espacio de relaciones institucionalizado con posiciones definidas para una cantidad limitada de agentes. Estos son exactamente los senderos de la crítica que viene construyendo el sociólogo francés Bernard Lahire sobre el modelo de Bourdieu³.

Primero, en La Culture des Individues, Lahire se dedicará al estudio intensivo de prácticas y preferencias culturales en escala individual, constatando la inexistencia de ciertas presuposiciones incluidas en el modelo de campo y habitus, necesarias para explicar el efecto general de la "distinción". A pesar de la rotundidad teórica del esquema general, los estudios empíricos no ratifican la coherencia interna que se le presupone al habitus, al constatar la gran frecuencia con la que distintos sujetos de un grupo social homogéneo, o incluso el mismo sujeto, combinan indiscriminadamente prácticas y preferencias culturales dominantes y dominadas, creando "disonancias"

3 Un primer esbozo de esta crítica, todavía analítica y no propositiva, se encuentra en el fundamental ensayo "Campo, contra-campo, fuera de campo". En éste, Bernard Lahire desmenuza teóricamente los elementos fundamentales de la teoría del campo, un modelo del que la sociología francesa e internacional han venido abusando de forma acrítica. Tomando como ejemplo concreto los estudios de Bourdieu sobre el "campo literario", Lahire levanta algunos puntos que serán el núcleo de posteriores desarrollos, como la falta de un estudio concreto de las prácticas y características estrictamente literarias de los textos y los escritores, o la indefinición y ambigüedad sobre los efectos de la "autonomización" del campo (Lahire, Cатро 18-30). 
intra e interindividuales. Por ejemplo, podríamos encontrar sujetos que combinan prácticas culturales muy legítimas, como la lectura continuada de literatura clásica, con prácticas culturales poco legítimas, como la preferencia por programas de televisión de entretenimiento. La observación empírica a escala individual destaca la importancia de los contextos de práctica, haciendo comprensibles constelaciones de prácticas y preferencias que en principio parecerían incomprensibles o sorprendentes, como por ejemplo: el trabajador de un restaurante fast-food que lee Dostoievski en sus horas libres, pero cuando vuelve a casa se relaja con una telenovela o con unos cómics estadounidenses.

El estudio de la diversidad de prácticas culturales, que lleva a la desestabilización de las rígidas imágenes preconcebidas (el sujeto de "gusto erudito" frente al sujeto de "gusto popular", como caricaturas incomunicadas) se prolonga con el estudio de "la condición literaria", indagando en detalle sobre los estilos de vida y la situación de trabajo de escritores contemporáneos franceses ${ }^{4}$. Uno de los grandes hallazgos de este estudio es el destaque y definición de la "doble vida" generalizable para la gran mayoría de los escritores en régimen de mercado que, vista su imposibilidad de vivir exclusivamente de las rentas que produce su actividad literaria, están obligados a compatibilizar esta actividad con un "segundo empleo" en ámbitos paraliterarios (conferencias, talleres de escritura creativa, redacción periodística de artículos o columnas, etc.) o extraliterarios (trabajos remunerados de todo tipo). Este hecho fundamental en la vida de los escritores, que forzosamente será determinante para sus estructuras de percepción y disposiciones a la acción (el habitus), no era observado en el modelo bourdieusiano, que se limitaba a definir el "habitus escritor", idéntico para todos los casos. ¿Acaso serían equiparables, en términos de habitus: un profesor universitario que escribe poesía erudita contemporánea y alguna columna crítica en revistas especializadas, aunque apenas obtiene dinero con estas actividades; a un escritor de novelas policiales que escribe a tiempo completo y vive de sus derechos de autor; o a un taxista que por las noches, después de la telenovela, escribe crónicas o breves cuentos sobre el día a día de su oficio, para publicarlas en pequeños volúmenes autoeditados? Si el proceso de identificación social como "escritor" se asocia simplemente a la práctica continuada de la escritura y a

$4 \quad$ En el artículo anteriormente citado, destaco algunas características del modelo de investigación y las principales conclusiones de La condition littéraire. La double vie des écrivains, especialmente en lo relativo a la "autonomía literaria" (Souto 35-43). 
la publicación de sus producciones, los tres sujetos serían definibles como escritores. Pero es evidente que las diferentes condiciones de vida de unos y otros no serán en absoluto irrelevantes, ni para su actividad literaria, ni para el resto de los universos de actividad.

Es por eso que las aperturas conceptuales propiciadas por los estudios de Lahire en sociología de la literatura son tan valiosas para el estudio de la literatura marginal periférica, permitiendo formular nuevas indagaciones e hipótesis interpretativas. Al estudiar como prácticas y preferencias culturales heterogéneas pueden ser compatibilizadas por el mismo grupo o individuo, y al destacar la pertinencia de la "doble vida" de los escritores, conseguimos acercarnos a un retrato más apurado de este grupo de escritores, donde es posible atender simultáneamente su actividad literaria ("ser escritor") y la experiencia cotidiana de la violencia y la desigualdad ("ser periférico"), sin que la observación de una característica emborrone la otra.

\section{"MIRADA INTERNA" O "PACTOS DE LECTURA MÚLTIPLES"}

Podemos comenzar, por tanto, a hablar de esa literatura extraña y generalmente ignorada por el campo de la crítica literaria, cuyos autores no presentan las características preponderantes que mencionaba el artículo de El País para el escritor brasileño contemporáneo: blanco, urbano, de clase media ${ }^{5}$. Y es que

\footnotetext{
5 Evidentemente, cada uno de estos tres elementos ("blanco", "urbano", "clase media") y sus respectivos antónimos indican poco más que posiciones polares en procesos de identificación relacionales y complejos. La idea "blanco" hace referencia al factor étnico-racial, lo que haría necesaria una discusión sobre el racismo en Brasil e ideas como "mestizaje" o el mito ideológico de la "democracia racial" (Munanga). Al hablar de "urbano", es necesario pensar en "periferia" como un elemento simbólico antitético, que se articula en operaciones discursivas que construyen esa polaridad, haciéndose audibles tanto en el discurso de estos escritores como en el habla corriente de la elite brasileña: las oposiciones entre términos como favela, morro, quebrada, perifa y términos como centro, asfalto, bairro nobre, etc., reforzadas con expresiones como "o mundo é diferente da ponte pra cá" (verso del grupo de rap Racionais $M C s$ ya convertido en expresión común al sur del puente João Dias, que separa el centro de la Zona Sur de São Paulo). El término "clase media" también es especialmente espinoso por su utilización contemporánea en el discurso político brasileño, donde ciertos grupos pretenden hacer valer la hipótesis según la cual, en las últimas décadas, se estaría consolidando una "nueva clase media" brasileña. Una evaluación sociológica de este argumento implicaría considerar no solo indicadores económicos (renta, consumo, etc.), sino también relaciones
} 
el principal elemento de articulación y aglutinación de esa literatura marginal periférica remite antes a procesos de identificación y características sociales de los escritores, que a características lingüísticas de las obras (donde en general encontramos un alto grado de heterogeneidad). Si por algo se diferencia esta literatura, es por estar producida por sujetos exteriores a esa élite letrada, a esa minoría dominante: se trata de escritores negros, pardos o mestizos, habitantes de favelas, periferias urbanas u otros espacios de exclusión, que combinan o combinaron su actividad literaria con los trabajos más duros de la cadena productiva, o incluso con actividades en conflicto con la ley. En el campo académico, la recepción crítica de estos escritores no ha sido unánime, como constata el temprano artículo de Fernando Villarraga, detectando que

algumas vozes dos campos acadêmico e jornalístico advertem alarmadas sobre os riscos, as confusões e as promiscuidades que supostamente comporta a cada vez mais visível onda dos marginais, com suas afirmações sobre a condição de serem escritores e seus desejos de se verem reconhecidos como parte da literatura nacional (Villarraga 35).

Una pequeña muestra de las "muchas desconfianzas y sospechas enormes" que generaron en su inicio estos textos se puede encontrar en la importante obra crítica de Karl Erik Scholhammer sobre la Ficção Brasileira Contemporânea, donde esta autodenominada literatura marginal periférica es clasificada como "neo-documentalismo" sin "ninguna innovación" ni "valor literario" (98105). Tal vez, el motivo del desprecio se deba a la importancia de ciertos elementos paratextuales y extratextuales para la construcción del efecto estético, elementos que la crítica no está habituada a considerar y que, de cierta forma, podrían entenderse como amenazas a la "autonomía literaria".

Porque precisamente ese concepto extraño citado por Scholhammer -"neodocumentalismo"- apunta a uno de los rasgos textuales que más controversias suscita al hablar de este grupo literario. La "mirada interna", que múltiples lecturas críticas han atribuido de forma poco concreta a las obras de esta literatura marginal periférica, parece referirse a una cualidad textual de las obras (el retrato realista, detallado y empático con los protagonistas, de

de poder y derechos sociales (Souza). En cualquier caso, para los procesos de identificación que importan aquí, podemos decir que "clase media" sería casi equivalente a "élite" o "clase dirigente", y se opondría tanto a "clase trabajadora" como a los habitantes de los espacios de exclusión antes mencionados: favelados, periféricos, etc. 
esos universos de exclusión donde se ambientan las obras) a partir de rasgos biográficos de sus autores (su origen e identificación con estos espacios: favelas, quebradas, periferias, cárceles, etc.).

La conocida novela de Paulo Lins Cidade de Deus (1997) abrió el ciclo de esta nueva producción. La veta virgen no apuntaba tanto a la representación de la violencia urbana (camino previamente trillado por escritores brasileños como Rubem Fonseca, y continuado por otros más recientes como Patricia Mello, Marçal Aquino, o Fernado Bonassi ${ }^{6}$ ), sino a lo que desde el primer momento se llamó el olhar interno, la mirada interna. Con una reconstrucción de la historia de la favela que da título al libro, la recepción de la obra se centró desde el primer momento en "el punto de vista interno", destacando el origen biográfico del autor (antiguo habitante de esta favela) como principal aporte del mismo ${ }^{7}$. El momento más importante para la consolidación de esta lectura se da con la reseña del importante crítico Roberto Schwarz, poco después del lanzamiento de la obra, publicada en el cuaderno cultural del diario Folha de São Paulo. En ese momento ya se menciona esa "mirada interna": "O interesse explosivo do assunto, o tamanho da empresa, a sua dificuldade, $o$ ponto de vista interno e diferente, tudo contribuiu para a aventura artística fora do comum" (Schwarz 163, énfasis nuestro).

Por la relevancia del crítico y del medio, esa reseña fue muy importante para la divulgación del libro, incluso en el escenario internacional (con múltiples traducciones) y en la industria cultural (con su exitosa adaptación cinematográfica). Es por eso que, quince años después de su lanzamiento, la editora Companhia das Letras todavía utiliza las palabras de Schwarz

6 Sobre esta tendencia, anteriores comentarios críticos habían introducido términos como "realismo feroz" (Candido, Nova) o "brutalismo" (Bosi).

La recepción centrada en la biografía del autor fue tan unánime, que el reseñista habitual de Folha de São Paulo, Marcelo Rubens Paiva, se vio obligado a matizar esta lectura, contrarrestando esta interpretación y destacando la experiencia poética de Lins: "Ex-favelado negro escreve romance financiado pela Fundação Vitae que, com a indicação de Roberto Schwarz, um dos maiores críticos literários brasileiros, é publicado pela Companhia das Letras. É dessa maneira que parte do mercado reage à publicação de Cidade de Deus, de Paulo Lins. Mas essas palavras embutem uma apresentação capenga e lograda. O escritor não surgiu do nada e nem fez um exótico exercício de como é o dia-a-dia de uma favela carioca. Lins, 38, é poeta de carteirinha. Participou, no começo dos anos 80, do grupo Cooperativa de Poetas, braço carioca do movimento de poesia independente. Estudou literatura e português na UFRJ (Universidade Federal do Rio de Janeiro). Publicou, em 86, Sobre o Sol, livro de poesias, pela editora da universidade" (Paiva). 
como reclamo publicitario, junto con otros comentarios que apuntan en la misma dirección:

"Na Cidade de Deus, a lei do mais forte se estabeleceu, logo suplantada por aquela do mais cruel, substituída por sua vez pela do mais selvagem. Paulo Lins conhece bem essa história". Le Monde, França.

"Vinte anos de vida numa favela narrados por dentro. Um verdadeiro fenômeno". El País, Espanha (Lins, contraportada. Énfasis nuestro).

Esa "mirada interna" sirve como reclamo publicitario, herramienta de promoción mercadológica de la obra y de consagración del autor en el juego literario. Desde un punto de vista más ceñido a la crítica literaria, esta idea cobra un carácter más apurado si hablamos de "pactos de lectura múltiples" La importante "carga testimonial", con la que el autor utiliza su trayectoria de vida como elemento fundante de su producción ficcional, no siempre se formulará de forma unívoca, sino envuelta en diferentes juegos y paradojas de gran complejidad. Como se desprende del análisis de los elementos paratextuales que acompañan el libro Memórias de um sobrevivente (2001), escrito por el expresidiario Luiz Alberto Mendes durante su reclusión, “estes não apontam para um gênero indubitável, e sim para um pacto de leitura múltipla: por vezes a obra é apresentada como autobiografia, por vezes como testemunho e, outras, como romance" (Scapini 46). Estos "pactos de lectura múltiples" devuelven al escenario crítico cuestiones referentes a las convenciones del "realismo" en sus diferentes contextos de enunciación, que poco a poco venían siendo sustituidos por debates estrictamente vinculados a aspectos formales del texto.

Usando este recurso, Cidade de Deus marca un hito en la literatura brasileña contemporánea, recibido como un "acontecimiento inédito" que surge contrariando las expectativas generales del campo literario brasileño, del que casi se puede escuchar el grito entre sorprendido y alarmado: "¡un

8 El concepto "pacto de lectura múltiple" fue propuesto por Carla Scapini (46-50). Con este se refiere a los movimientos de oscilación inestable entre los rasgos de lo documental, lo autobiográfico y lo novelesco, donde el autor establece diferentes, contradictorios y simultáneos "pactos de lectura" con el lector, desde el "pacto ficcional" (Umberto Eco) al "pacto autobiográfico" (Philippe Lejeune). Aunque el concepto teórico se construye sobre el análisis de la obra Memórias de um sobrevivente (Luiz Alberto Mendes, 2001), su uso es muy pertinente para otros autores y obras de la literatura marginal periférica presentados aquí, como Cidade de Deus (Paulo Lins 1997) o Capão Pecado (Ferréz, 2000). 
favelado que escribe!”. Releyendo el citado artículo de El País, vemos que, aún hoy, Paulo Lins sigue siendo considerado una excepción insólita, como declara el escritor (joven, blanco, de clase media) Antonio Prata:

Em toda minha vida escolar, nunca tive um colega de escola negro, embora grande parte da população seja de negros. Dedica-se à literatura apenas aquele que está alfabetizado e a maioria é de classe média para cima e vive em grandes cidades. Há, claro, exceções, como em tudo. Talvez o livro mais importante dos últimos 20 anos seja Cidade de Deus, de Paulo Lins: um negro que veio da periferia (Prata, cit. en Ballesteros).

Esta reacción del campo literario dominante, que siente haber realizado un descubrimiento de lo insólito, es precisamente el tema de la tesis de Mario Augusto Medeiros da Silva, que mediante el estudio de las trayectorias literarias y las reacciones críticas, emparenta a escritores periféricos contemporáneos como Paulo Lins o Ferréz con casos anteriores semejantes, como el de Carolina de Jesús o los escritores integrantes de Quilomboje 9 . Para esto, es importante la detallada reconstrucción de la carrera literaria de Paulo Lins, desde la juventud universitaria y su cercanía a poetas como Paulo Leminski, pasando por su participación como "investigador de campo" en el proyecto antropológico de Alba Zaluar sobre violencia en las favelas, hasta su "descubrimiento literario" por el crítico Roberto Schwarz, que terminó ejerciendo labores de mecenazgo para su publicación y consagración (Silva 327-387). Esta trayectoria oscilante, desde las primeras tentativas poéticas a la investigación antropológica, y la retomada de la lírica en la ficcionalización de lo real, es recordada por Schwarz en su famosa reseña de Cidade de Deus:

[...] talvez se possa dizer que em Cidade de Deus os resultados de uma pesquisa ampla e muito relevante -o projeto da antropóloga Alba Zaluar sobre 'Crime e criminalidade no Rio de Janeiro'- foram ficcionalizados do ponto de vista de quem era o objeto do estudo, com

\footnotetext{
Grupo literario brasileño actuante desde finales de los setenta, integrado por escritores negros. Entre sus principales actividades está la publicación de los Cadernos Negros, desde 1978 hasta el presente. Actualmente, varios escritores integrantes de la literatura marginal periférica interactúan también con este grupo y publican en los Cadernos Negros, como Adelmiro Alves ("Sacolinha") o Allan da Rosa. Más información en la web de Quilomboje: $<$ http://www.quilombhoje.com.br> (consultado 14/05/2014).
} 
a correspondente ativação de um ponto de vista de classe diferente (mas sem promoção de ilusões políticas no capítulo). Significativa em si mesma, essa recombinação de fatores tem um tom próprio, que no conjunto funciona vigorosamente, embora destoando da 'prosa bem-feita'.

[...] A importância deliberada e insolente da nota lírica, que faz frente ao peso esmagador dos condicionamentos pela miséria, dá ao romance um traço distintivo, de recusa, difícil de imaginar num escritor menos inconformado. Seria interessante refletir sobre a ligação entre esse lirismo improvável e a força necessária ao deslocamento do ponto de vista de classe - de objeto de ciência a sujeito da ação-que observamos a propósito do papel da enquete social na obra (Schwarz 169-170).

Sin embargo, esa aparente excepcionalidad de Lins (mencionada por Antonio Prata o implícita en los comentarios de Schwarz) no se contrasta en la realidad empírica, donde encontramos muchos otros casos de escritores contemporáneos de una condición social semejante a la suya. Tal vez el caso más conocido sea el de Ferréz que pocos años después de Cidade de Deus publica Capão Pecado (2000).

Un buen resumen de la trayectoria biográfica y literaria de Ferréz es el realizado por Érica Peçanha do Nascimento (Vozes 200-215), en el que nos basamos para el breve relato que sigue. Pseudónimo de Reginaldo Ferreira da Silva, Ferréz adopta un nombre literario, imitando la práctica habitual entre los rappers de Capão Redondo, estigmatizado barrio periférico del extremo sur de São Paulo. Con una experiencia escolar fugaz y sin mucha trascendencia, Ferréz se incorpora joven al mercado de trabajo en las condiciones precarias típicas en las periferias, realizando las labores más diversas: vendedor en una panadería, ayudante de albañil, vendedor ambulante de escobas, freidor en un fast-food o archivista en una empresa de recursos humanos. Con el patrocinio de esta última empresa lanza su primer libro de poesía, Fortaleza da Desilusão (1997), en edición de autor e independiente de todo esquema de distribución. La indiferencia mediática y crítica de este estreno literario contrasta radicalmente con el desmesurado interés que despertó su siguiente lanzamiento, la novela Capão Pecado (2000). En esos tres años, el autor se aproximó al movimiento hip-hop, adoptando su estética y traduciéndola en el medio literario, de forma que en la primera edición de la novela se incluían colaboraciones de rappers de la Zona Sur de São Paulo, como Mano Brown, Cascão o Negredo. Esta propuesta literaria, de cierta forma inspirada por Cidade de Deus, fue noticiada en grandes medios de comunicación incluso 
antes de ser publicada, como el diario Folha de São Paulo, que el 6 de enero de 2000 publicaba:

Desempregado do Capão Redondo escreve romance baseado em histórias verdadeiras de um dos bairros mais violentos de SP; livro, sem editora, está pronto, mas o autor muda trechos quando algum personagem morre na vida real (Folha de SP, cit. en Nascimento, Vozes 205).

Esta presentación publicitaria, que nos remite a los mencionados "pactos de lectura múltiples", se repiten en las apariciones mediáticas del autor, como en su entrevista en el programa de televisión O Programa de Jô Soares ${ }^{10}$, un importante late show que fue fundamental para la rápida difusión y venta de la novela, donde el interés de la entrevista se centra más en la experiencia de vida del autor que en la obra literaria. En ocasiones, el propio autor utiliza este "pacto de lectura mútliple" como una forma de legitimación, confrontando su conocimiento directo del tema con las representaciones estereotipadas de la favela realizada por "escritores de la élite", como cuando sentencia que "A Patricia Melo retrata o que não conhece, eu não falo sobre a elite porque não conheço" (cit. en Nascimento, Vozes 212). En cierta forma, el argumento que se trasluce tanto en las declaraciones públicas del autor, como en los paratextos y elementos que acompañan estas publicaciones, es siempre el mismo: "quien mejor narra la periferia es quien vive en ella".

Este recurso literario, que se apoya en técnicas lingüísticas como el uso de jergas periféricas y la descripción de ambientes y prácticas típicas de estos lugares, fue muy efectivo para la difusión de la obra de Ferréz en los medios periféricos, y se mantuvo en obras posteriores del autor como la novela Manual Prático do Ódio (2003) o el libro de cuentos Ninguém é inocente em São Paulo (2006). Pero también fue importante para la consolidación de la trayectoria literaria del escritor, como muestra que estos dos libros fueran lanzados por la importante editorial Objetiva (Grupo Santillana), que también reeditó Capão Pecado, tras una disputa judicial del autor (relativa

10 Emitida en el año 2000, poco después del lanzamiento de Capão Pecado, la entrevista completa se puede ver en $<$ https://www.youtube.com/watch? $\mathrm{v}=\mathrm{SCb} 30 \mathrm{IpfOxM}>$ (Acceso 14/05/2014). Vemos, por ejemplo, cómo el presentador Jô Soares muestra escaso interés por el libro de poesía Fortaleza da desilusão, que el escritor le ofrece como regalo. 
al pago de derechos de la obra) con la pequeña editora que había lanzado la novela (Labortexto).

Con el destaque conseguido con Capão Pecado, Ferréz es invitado a participar como columnista mensual en la revista Caros Amigos, publicación nacional vinculada al discurso político de izquierda. Esto le permite realizar un emprendimiento de gran importancia ${ }^{11}$ para la aglutinación y articulación de la literatura marginal periférica: la organización de tres números especiales de esta revista con el tema Literatura Marginal (2001, 2002 y 2004) que, a modo de antologías, recogieron los textos de más de 40 autores de condición social semejante, muchos de ellos inéditos hasta el momento. En este mismo sentido, el escritor fundó en Capão Redondo el proyecto editorial Selo Povo, para publicar autores periféricos inéditos y lanzar libros a precios populares, totalizando hasta el momento cuatro títulos publicados ${ }^{12}$.

Como vemos, en un primer momento, que coincide con el cambio de siglo, el campo literario brasileño se muestra muy interesado en la producción literaria periférica, aunque solo cuando ésta explota el recurso de los "pactos de lectura múltiples" para construir retratos realistas de estos ambientes, con especial atención en temas como la violencia, el crimen o la miseria. Otras producciones literarias periféricas de ese mismo período no ganan tanto destaque mediático, aunque a pesar de esto crecen de forma autónoma, tanto en volumen de publicación como en diversidad temática y formal, a partir de circuitos literarios independientes que se aproximan a la consolidación de un "sistema literario" alternativo (como veremos en el siguiente apartado).

Al mismo tiempo, observando las publicaciones más recientes de Paulo Lins y Ferréz, parece que ambos vienen sintiendo una saturación de las posibilidades expresivas del recurso a los "pactos de lectura múltiples", o en todo caso, el hastío personal de los autores con esta opción técnica. Esto es más evidente en el caso de Paulo Lins, quien desde el primer momento rechazó la etiqueta de la "Literatura marginal" y reivindicó su condición de "escritor puro" y creador de "ficciones" (Nascimento, Vozes 59), tal

11 La importancia de estas revistas para la articulación del grupo como movimiento literario, y para la "entrada en escena" de nuevos autores, fue destacada por Nascimento (Vozes 52-75) y por Silva y Tennina.

12 Los libros lanzados son: Oh, margem! Reinventa os rios! (Cidinha da Silva, 2011), Sob o azul do céu (Marcos Teles 2011), Amazônia em chamas (Catia Cernov 2010), y Cronista de um tempo ruim (Ferréz 2010). Para más información, consultar: <http://www.selopovo. blogspot.com.br> (consultado 14/05/2014). 
vez temeroso de que el foco en este tipo de recepción limitase la atención recibida por otro tipo de proyectos literarios, no necesariamente vinculados a su "experiencia biográfica". Tras quince años sin publicar, Desde que o samba é samba (2012), la nueva novela de Paulo Lins se remonta a los orígenes del samba en las primeras décadas del siglo XX, con una exploración literaria del universo afro-brasileño que difícilmente puede ser leído en clave "autobiográfica"13. Al mismo tiempo, Ferréz también regresa a la novela tras casi diez años sin tocar el género. Deus Foi Almoçar (2012) es una obra extraña, todavía relativamente incomprendida, en la que Ferréz realiza el acercamiento de la cultura popular al conocimiento esotérico y al ocultismo (está muy presente la figura del médico ocultista Papus, con sus conceptos de "portal" y "astral"), con abundantes referencias a universos culturales tan dispares como la ciencia-ficción, la ufología o los cómics estadounidenses y underground brasileños. Realizando una deconstrucción psicológica del protagonista (Calixto, un archivista depresivo de clase media, recientemente divorciado y separado de su hija), Ferréz parece apartarse de lo cotidiano periférico y su experiencia biográfica, para esbozar una crítica filosófica más profunda de la civilización moderna occidental, aproximándose tal vez a escritores como Dostoievski o Hermann Hesse (ambos frecuentemente citados como referencias literarias del autor).

Estos desdoblamientos literarios nada más ratifican la amplitud y la heterogeneidad de la literatura marginal periférica. Aunque en un primer momento el campo literario recibió esta tendencia como un "neodocumentalismo" sin ningún "valor literario", hace tiempo que los autores oriundos de las periferias realizan propuestas de los tipos más variados, sin preocuparse de que la crítica hegemónica no parece prestar excesivo interés al asunto.

13 Sin embargo, la posible lectura en clave "documental" generó una tímida disputa pública entre Lins y el historiador Sérgio Cabral. Para éste, autor de varios libros sobre el nacimiento del samba en el Rio de Janeiro de las primeras décadas del siglo XX, Lins incurre en varios "escorregões históricos", como la presentación de varios compositores "adotando um comportamento que nada tinha a ver com a realidade" (Cabral). En legítima réplica publicada en el mismo diario, Lins habla de la libertad que le permite la ficción, contra la excesiva atención dada a personajes históricos responde que "Grupos sociais são os protagonistas dos meus romances", y finalmente, argumenta que "Na literatura vale mesmo não o que aconteceu, mas o que poderia ter acontecido". 


\section{SARAUS: INDIFERENTE A LA CRÍTICA, LA LITERATURA EXPLOTA EN LAS PERIFERIAS}

La vida literaria hace tiempo que ha explotado en las periferias paulistanas. En el mismo período en el que la crítica trataba como "excepciones insólitas" los casos de Ferréz o Paulo Lins, una interesante red de saraus periféricos se iba articulando en los diferentes extremos de la ciudad. Estos saraus son encuentros abiertos en diferentes locales públicos de las periferias de São Paulo (principalmente bares o botecos), en los que diferentes ciudadanos se encuentran para recitar poesía, intercambiar libros o simplemente debatir sobre la vida pública de la ciudad. La palabra sarau tiene su origen en encuentros poéticos realizados por diferentes grupos intelectuales, como los encuentros de los poetas modernistas en los salones de las elites paulistanas (Nascimento, É tudo 32). En un interesante ejercicio de antropofagia periférica, los poetas y escritores periféricos se apropian de este término y lo adoptan para designar sus encuentros, que presentan características algo diferentes a los encuentros de la burguesía. En estos encuentros, la práctica literaria adopta una dimensión lúdica y festiva, donde la soledad y recogimiento de la lectura silenciosa individual se sustituye por la exposición corporal del "poeta-ciudadano" ${ }^{14}$, que al hacerse presente junto a su público se ve obligado a trabajar la dimensión performática de lo literario. El grupo pionero que debe tomarse como referencia para este tipo de encuentros es el sarau de la Cooperifa, movilizado principalmente por el poeta Sérgio Vaz y un grupo cercano de colaboradores. Actuante desde 2001 en el bar do Zé Batidão, situado en Jardim Ângela (Zona Sur de SP), el sarau ha sido densamente descrito en la investigación etnográfica de Érica Peçanha do Nascimento,

14 En un manifiesto redactado por Sérgio Vaz, se introduce la figura del artista-cidadão, como un sujeto comprometido con su comunidad, una identidad que puede ser adoptada por cada persona que declame en un sarau, independientemente de ser un texto autoral o no. "Desta forma, a poesia, como qualquer outro gênero literário, é pensada, antes de tudo, como um meio de expressão individual e coletiva, e menos em suas formalizações estéticas. Não se trata, portanto, de submissão dos poetas do sarau à lógica estrita de reconhecimento e consagração de instâncias como mercado editorial, academia ou crítica especializada, tampouco de a literatura ser percebida como uma vocação. Nos saraus, por meio da prática poética, os poetas estão agenciando também suas subjetividades, modos de ser e estar no mundo. E como poetas colocam-se num outro lugar que não apenas o de trabalhadores, vítimas, carentes, desprovidos de oportunidades, excluídos sociais, entre tantas outras identidades arrogadas e assumidas por eles" (Nascimento, É tudo 87). 
fruto de su tesis doctoral ${ }^{15}$. Más allá del grupo de la Cooperifa, un ingente número de saraus ha proliferado por las diferentes periferias de São Paulo durante la última década, como ha mapeado en detalle Lucía Tennina. La frecuente circulación de autores y lectores por estos saraus, y la diversidad de perfiles demográficos y autorales que podemos encontrar en los mismos (poetas repentistas con ascendencia nordestina, jóvenes rappers, ancianos que declaman poemas clásicos de memoria, actores aficionados, representantes de diferentes movimientos sociales, trabajadores de los más distintos ramos que buscan saciar su curiosidad literaria, etc.), hace que este circuito de saraus periféricos se convierta en un "sistema literario"16 independiente, paralelo al de la "literatura oficial" reconocido por los medios de comunicación o por las instituciones públicas de políticas culturales. El hecho de que, junto a las declamaciones orales, los diferentes saraus sirvan como plataforma de lanzamiento y venta de libros, permite que los autores periféricos distribuyan sus obras de forma autónoma, sin depender de los circuitos convencionales (editoras, distribuidoras, librerías, etc.). Después de escribir su obra, un autor puede imprimir su libro y pasar a venderlo por los diferentes saraus de la ciudad ${ }^{17}$, de forma que aunque las rentas derivadas de esta actividad no le permitan prescindir de otras actividades remuneradas, al menos consigue recuperar la inversión o reducir los costes, además de contactar un público lector que podrá, a su vez, apreciar y difundir su obra.

Sin espacio para citar con un mínimo de rigor la gran cantidad de nombres que integran el actual movimiento de la literatura marginal periférica

15 También existe un interesante reportaje documental sobre el sarau da Cooperifa, cuyo título, Povo lindo, povo inteligente! (DGT Filmes, 2007), hace referencia al lema que se declama colectivamente al inicio de cada encuentro. El documental completo está disponible en https://www.youtube.com/watch?v=wwIy5pyoq0M, (consultado 14/05/2014).

16 Utilizamos este concepto en el sentido definido por Antonio Candido, para el que un "sistema literario" es un cuerpo vivo y articulado, cuyos elementos son el trío "escritor", "público" y "obra". Esto es, "um conjunto de produtores literários, mais ou menos conscientes do seu papel", "um conjunto de receptores, formando os diferentes tipos de públicos, sem os quais a obra não vive", y "um mecanismo transmissor, que liga uns aos outros" (Literatura 17-40).

17 Una lista sistemática realizada entre los años 2005 y 2010 muestra al menos 72 títulos lanzados solo en el sarau da Cooperifa (Nascimento, É tudo 115). Si consideramos que esta práctica es habitual en el resto de saraus periféricos de la ciudad, aun sin disponer de datos sobre la cantidad de copias vendidas de cada título, podemos intuir la capacidad de distribución paralela de este circuito. 
brasileña ${ }^{18}$, quisiéramos llamar la atención sobre la obra de Allan da Rosa, por significar un contrapunto interesante para la argumentación que venimos elaborando, al construir "otra mirada sobre la periferia" (Patrocínio 2011). Con un perfil polifacético, la obra de Da Rosa se despliega en verso, prosa y teatro, del cordel orientado a un público infantil, a la poesía erótica, pasando por las columnas periódicas que firma en la revista Fórum São Paulo ${ }^{19}$, donde la crónicas de actualidad se presentan con su punto de vista crítico y una gingada prosa poética. Oriundo de las periferias del sur de São Paulo, y con una formación literaria que debe mucho a los saraus, la trayectoria biográfica e intelectual de Allan da Rosa está marcada por su paso por la Universidad de São Paulo. Con esto, su obra establece interesantes puentes de comunicación entre los registros oral y escrito, entre la matriz africana y la modernidad occidental, entre lo popular y lo erudito. Las posibilidades de diálogo e hibridación entre estos diversos universos culturales se articulan con una firme crítica al contexto social de desigualdad que las enmarca, a la jerarquización valorativa que tiene su faceta más violenta en el racismo y el elitismo cultural. Con una potente voluntad pedagógica y política, estas reflexiones teóricas ${ }^{20}$ se trasladan a la práctica con diferentes talleres de educación popular, narrados con detalle en su libro Pedagoginga, Autonomia e Mocambagem. Interesa de este escritor la combinación tensa de elementos afirmativos (la identificación con la literatura marginal periférica) con la valiente apropiación de elementos de otras matrices culturales, evitando que la definición socio-demográfica del movimiento literario se convierta en corsé castrador de los más ambiciosos proyectos literarios. Por ejemplo,

18 Por citar solo algunos nombres representativos, sin intención de sistematizar ni de jerarquizar, podríamos mencionar a Alessandro Buzo, Rodrigo Ciríaco, Cidinha da Silva, Adelmiro Alves “Sacolinha”, Toni C., Renan Inquérito, Roberta Estrela D'Alva, Dugueto Shabazz, Renan Inquérito, Akins Kinté, Elizandra Souza, etc. Pero sería necesario también mencionar algunos grupos poéticos o saraus como los Mesquiteiros, Quilombaque, Poetas Ambulantes, Elo da Corrente, Sarau da Brasa, Perifatividade, etc.

19 Sección À beira da palavra, todos los artículos están disponibles en: http://www. revistaforum.com.br/abeiradapalavra/ (consultado 14/05/2014). Con el mismo título, Da Rosa dirigió un programa de radio sobre literatura popular, negra, periférica o indígena, con entrevistas a autores y lecturas de textos. Los programas están disponibles en: http://www. edicoestoro.net/radio/beira-palavra.html (consultado 14/05/2014).

20 Ver su disertación de maestría, defendida en la Facultad de Educación de la USP: Imaginário, corpo e caneta: Matriz Afro-brasileira em Educação de Jovens e Adultos (Da Rosa 2009). 
el retrato de la violencia urbana periférica basado en los "pactos de lectura múltiples", que habíamos visto en las primeras obras de Ferréz o Lins, no aparece necesariamente en los textos de Da Rosa, más abierta a otro tipo de miradas. La apertura que significa este punto divergente de la obra de Da Rosa dentro de la literatura marginal periférica fue destacada por Patrocínio, que venía a ratificar a partir del análisis de las obras, lo que Da Rosa declaraba sutilmente:

Eu percebo que [na literatura marginal periférica] tem pessoas que estão afim de escrever um texto para levantar a rapaziada e lembrar que existiu o cangaço. E que quer que o livro seja uma parabélum mirada na testa do volante. E o outro que já quer perguntar "E se o passarinho não tivesse asas, e se o passarinho tivesse escamas?" Ele não está afim de trazer o cangaço. Ele está afim de trazer o impossível (Da Rosa, Parabelum 9).

De esta forma, Da Rosa sitúa su producción en los límites de lo imaginario, sin que la sutileza reste peso político a su apuesta. Con este punto divergente solo queríamos señalar la riqueza y diversidad interna de este movimiento literario, cuando podría decirse que ya completa una década en su andadura colectiva. Los citados estudios de Érica Peçanha do Nascimento, Lucía Tennina, Carla Scapini, Mario Medeiros da Silva o Paulo Tonani do Patrocínio son muestras del incipiente interés que el campo académico viene prestando a la producción literaria periférica ${ }^{21}$, el que, sin embargo, no nos permite afirmar que la producción de este grupo literario sea una prioridad en la agenda crítica dominante. ¿Es aún posible, y deseable, un mayor acercamiento entre las instituciones nomotéticas del campo literario y los escritores de las periferias? ¿Qué podemos esperar de esta relación?

$21 \quad$ Una búsqueda superficial en el banco de tesis y disertaciones del principal organismo universitario brasileño <http://www.capes.gov.br/servicos/banco-de-teses $>$, muestra no menos de una treintena de trabajos realizados en la pasada década sobre la literatura marginal periférica, especialmente sobre autores como Ferréz o Paulo Lins (consultado 14/05/2014). Sin embargo, sería necesario una revisión bibliográfica sistemática y profunda para poder dimensionar la trascendencia de estos estudios. 


\section{DESPRECIOS PERSISTENTES Y TENSIÓN PERMANENTE}

A pesar de que, como hemos visto, la literatura marginal periférica está fuertemente consolidada y cuenta con un buen público lector -en muchas ocasiones mayor que la literatura "blanca, urbana y de clase media"-, parece que esta literatura sigue infravalorada por el campo de la crítica académica y el periodismo cultural. Dos ejemplos concretos pueden ilustrar esta tendencia.

Primer momento: Octubre de 2013, Feria del Libro de Frankfurt, considerado el evento editorial más importante del mundo. Como cada año, una literatura nacional es homenajeada, centrando la atención de mesas temáticas, conferencias, debates, etc.: 2013 es el año de la literatura brasileña, por lo que, desde los dos años anteriores, un comité curatorial selecciona una lista de setenta escritores que representarán esta literatura en la feria. La importancia del evento para el campo cultural brasileño se refleja en la cobertura especial de diversos medios nacionales, como los diarios Folha de São Paulo y $O$ Globo. Y en medio de esta celebración, un periodista alemán del diario Tagesspiegel percibe sorprendido la hegemonía de escritores "jóvenes, blancos, de clase media", que contrasta con la imagen del "Brasil multicultural", llevándole a pensar en racismo ${ }^{22}$. La prensa brasileña recoge consternada la contundente respuesta de Paulo Lins:

\section{Paulo Lins diz que há racismo na lista da Feira de Frankfurt.}

"Eu sou o único autor negro dessa lista. Em que caso isso não é racismo?", afirma Lins, quando perguntado sobre a seleção, feita pelo jornalista Manuel da Costa Pinto, pela diretora de Livro, Leitura e Literatura da Fundação Biblioteca Nacional e por Antonio Martinelli, coordenador de programação do Sesc São Paulo. "É claro que depende o quê e quem se procure, e de que concepção se tenha da literatura. Essa lista não representa o Brasil”, diz (O Globo, 07/10/2013).

22 En entrevista a Paulo Lins realizada por Philipp Lichterbeck. El diálogo que levanta la polémica es el siguiente: "TS: Auch die Liste der 70 Autoren, die von der brasilianischen Nationalbibliothek ausgesucht wurden, um das Land auf der Frankfurter Buchmesse zu repräsentieren, wurde für ihre Unausgewogenheit kritisiert. / PAULO LINS: Ich bin der einzige schwarze Autor auf dieser Liste. Wenn das kein Rassismus ist?!" [TS: La lista de 70 autores seleccionada por la Biblioteca Nacional brasileña, para representar al país en la Feria del Libro de Frankfurt fue criticada por su desequilibrio. / PAULO LINS: Soy el único autor negro de esa lista. ¿Cómo puede eso no ser racismo? (Tagesspiegel, 07/10/2013). 
Otros escritores asociados a la literatura marginal periférica reaccionaron solidarizando con la reivindicación de Paulo Lins, como Ferréz en entrevista al diario Folha de $S P^{23}$, o Allan da Rosa, que en su columna de la Revista Forum escribía mordaz:

Mas dessa vez até da Alemanha reclamaram. Manjaram que estão levando um cartão postal ensolarado montado no meio da tempestade. Na banca de 70 escritores que vão representar o Brasil, esse país que a Avenida Paulista, a Vila Madalena e o Leblon estereotipam e desconhecem, mas que cabe bem fingir que fala de dentro quando palestram pra gringolândia; nesse iate de 70 escritores que na Feira de Literatura de Frankfurt vai abocanhar negociatas, bifes e bifês, ali tem um cisco preto, um borrãozinho indígena maculando a delegação. Machado de Assis, Lima Barreto... hoje não teriam nem editora pra selar seus parágrafos? Se a Garnier encadernou a manha dos contos do Malaco Machado, hoje a companhia limitada das altas letras não se rebaixaria ao chão, não arriscaria borrar sua palidez. Nórdicos somos, uai. Quer viver o verbo, camaradinho? Pra isso serve o microfone, desfile aí sua elegância, todo seu talento avermelhado nos olhos pela necessidade de sobrevivência e pelo gosto de malungar cada dia. E que essa praia da voz, beira de mares de chorar e de gargalhar, desenho de sonhos e pelejas, magnética ponte da compreensão, majestade nossa nascida no reio e na gana, não queira conhecer sua irmã e filha, a escrita. Que nossa realeza cintilante da saliva, de melodias e rasgos, cantada que faz chorar e dançada que arrepia, professora de desafios, timbres, solfejos e quadrinhas, não vá tomar um mingau na mansão da página. Ali as belas letras tem seus gansos e cães de guarda trilíngues, bem protegidas pelas fardas e heranças mas melindrosas em lembrar dos coletes e diplomas que lhe garantem o chá inglês (Da Rosa).

Segundo momento: Mayo de 2014, Feria del Libro de Buenos Aires, importante evento editorial latinoamericano. Participando en un stand central como ciudad invitada, São Paulo, de la que los organizadores destacan su producción periférica: "La ciudad es homenajeada en la $40^{\mathrm{a}}$ Feria Internacional del Libro

23 En entrevista, Ferréz se muestra igualmente crítico con el racismo institucional brasileño, identificándose con el movimiento negro a pesar de su piel clara, como insisten en destacar los periodistas: "Filho de negro com branca, Ferréz disse não ter se incomodado por ter sido deixado de fora do debate. 'Paulo Lins defendeu muito bem a causa"' (Folha de São Paulo, 12/10/2013). 
de Buenos Aires, una de las más grandes de América Latina. El arte y la literatura de las barriadas periféricas de la localidad brasileña dijeron presente en la capital argentina" ${ }^{24}$. El evento contó con el apoyo institucional de la Biblioteca Municipal "Mario de Andrade" de São Paulo, la presencia masiva de los saraus periféricos cuyos poetas fueron invitados, con el lanzamiento de varias traducciones al español de obras de este grupo, pero, sin embargo, la prensa cultural brasileña mostró escaso o nulo interés para desesperación del escritor Ferréz, quien escribía:

A mídia brasileira é mesmo um lixo, mais de 100 artistas da periferia aqui, fazendo uma verdadeira revolução cultural, representando nosso pais com muita propriedade e não tem uma nota na imprensa do nosso próprio pais.

Ontem terminamos a nossa mesa, com o Marcelino dizendo que talvez ficando nus geraria alguma nota.

Se fossem os autores eleitos pela elite que estivessem aqui se apropriando desse espaço, ai sim, eles falariam até como foi o café da manhã deles.

Mas isso não apaga o que está acontecendo aqui, tantos saraus, coletivos, escritores, poetas, artistas que representam todos as quebradas de São Paulo. E isso é fato.

(Ferréz, 10/05/2013, en su perfil de Facebook)

¿Qué conclusiones podemos extraer de estos dos momentos? En primer lugar, debemos notar la intensidad de la tensión vivida en el escenario literario brasileño, cuyas disputas no se traban simplemente entre diferentes autores o grupos estilísticos luchando por reconocimiento (como si el campo de las letras fuera un espacio totalmente autónomo), sino que muestran el cruce de fracturas sociales más amplias, como el racismo, el etnocentrismo de clase, o la perpetuación de desigualdades simbólicas y materiales. La literatura es así atravesada por el mundo, no solo por la representación de la realidad en las obras, sino en la misma organización de su vida interna, las relaciones entre los diferentes actores y las instituciones hegemónicas. 
En un país como Brasil, marcado por trágicas desigualdades históricas tanto a nivel material como simbólico, la literatura tendría potencial para ser un espacio de aproximación a la otredad, un camino para el reconocimiento mutuo sin pasar por el desprecio y la descaracterización de lo extraño. Sin embargo, observamos que esos encuentros entre grupos culturalmente diversos se dan de forma muy frágil, sin un intento real de acercamiento empático y sin prejuicios.

Por un lado, veíamos cómo la literatura marginal periférica se mantiene viva en su espacio geográfico y simbólico, constituyendo un "sistema literario" independiente y autónomo. Sin embargo, esto no implica que sus autores carezcan de interés en aproximarse al espacio de la literatura dominante, sea por intereses pragmáticos relacionados con recursos materiales (infraestructuras más amplias para la edición y la distribución) o en recursos propiamente literarios (referencias literarias, curiosidad por las formas canónicas, etc.). Por otro lado, sin embargo, observamos que el mundo de la crítica erudita y los medios de comunicación dominantes realizan una aproximación muy rasa, combinando una indiferencia generalizada con destellantes momentos de atención sobresaltada ("descubrimiento de lo insólito"), ante unos pocos casos concretos, cuando efectos estéticos insospechados satisfacen intereses extraliterarios. Es el caso, por ejemplo, de la articulación entre la representación de la violencia urbana construida por el "realismo feroz", cuyo impacto se refuerza por los "pactos de lectura múltiples", satisfaciendo el "voyeurismo de la clase media" del que ya hablara Candido (1987).

Esa aproximación de las instituciones hegemónicas de la cultura erudita a la literatura marginal periférica debe ser considerada, cuanto menos, insuficiente. Tal vez el problema resida en los mecanismos de producción del valor literario que describió Bourdieu, todavía muy ceñidos a parámetros culturales predominantes en las clases hegemónicas. Por ello, una valoración más rica de estas manifestaciones culturales exigiría uno de dos fenómenos: o las instituciones culturales dominantes realizan un ejercicio de ruptura con su etnocentrismo de clase, relativizando sus gustos socialmente determinados; o democratizan no solo los recursos técnicos y materiales de producción literaria (esto es, desde el dominio de la escritura hasta las tecnologías de publicación y distribución de libros... lo necesario para escribir y publicar libros), sino también los medios simbólicos de producción de valor literario (o sea, la crítica y los medios de comunicación, instituciones culturales como bibliotecas y museos... lo necesario para reconocer el valor de las obras). Sin estos cambios sociales, la comunicación entre estos universos culturales 
seguirá siendo balbuceante y estereotipada, y el escenario, el mismo que hasta ahora.

La biblioteca es un búnker en que el crítico, escondido entre muros de libros, se está perdiendo la revolución literaria que ya bulle en las calles, en un sistema literario independiente que no nos necesita. Mientras no se afirme la crítica periférica que generosa, nos traduzca ese mundo, los que estamos perdiendo somos nosotros, indiferentes en el silencio del sordo.

\section{BIBLIOGRAFÍA}

Ballesteros, Cecilia. "A nova literatura brasileira: jovem, branca, urbana e de classe média". El País - Brasil, 16/03/2014. Web. 10/05/2014. < http://brasil.elpais.com>

Bosi, Alfredo. História concisa da Literatura Brasileira. 1970. São Paulo: Cultrix, 2006.

Bourdieu, Pierre. Las reglas del arte. Barcelona: Anagrama, 1995.

Cabral, Sergio. "Apesar do título, livro de Paulo Lins tem mais intriga que samba". Folha de São Paulo, 29/04/2012. Web. 14/05/2014 <http://www1.folha.uol.com.br>

Candido Antonio. Literatura e sociedade: estudos de teoria e história literária. Rio de Janeiro: Ouro sobre Azul, 1967.

"A nova narrativa". A educação pela noite \& outros ensaios. São Paulo: Ática, 1987. 199-215.

De Jesús, Carolina Maria. Quarto de despejo. Diário de uma favelada. São Paulo: Livraria F. Alves, 1963.

Da Rosa, Allan. Pedagoginga, autonomía e mocambagem. Rio de Janeiro: Aeroplano, 2013. "O lapis teimoso". São Paulo: Revista Fórum - À beira da palabra. 03/10/2013.

Web. 14/05/2014. <http://www.revistaforum.com.br>

"Imaginário, corpo e caneta: Matriz Afro-brasileira em Educação de Jovens e

Adultos”. Disertación de Maestría en Educación. Universidad de São Paulo, 2009.

“A parabélum e o passarinho" (Entrevista). Revista eletrônica Darandina. Volume

3. No. 2, (2010). <http://www.ufjf.br/darandina/> Web. Acceso 14/05/2014

Ferréz. Fortaleza da Desilusão. São Paulo: edição do autor, 1997.

Capão Pecado. São Paulo: Labortexto, 2000 [2a. Ed. São Paulo: Objetiva, 2003].

Manual prático do ódio. São Paulo: Objetiva, 2003.

Ninguém é inocente em São Paulo. São Paulo: Objetiva, 2005.

Deus foi Almoçar. São Paulo: Planeta, 2012

Gonzaga, Sergius. "Literatura marginal”. Org. João Francisco Ferreira. Crítica literária em nossos dias e literatura marginal. Porto Alegre: Editora da Universidade, UFRGS, 1981.

Lahire, Bernard. "Campo, fuera de campo, contracampo". Colección Pedagógica Universitaria 37-38 (2002). 
La Culture des Individus. Dissonances Culturelles et Distinction de Soi. Paris: La Découverte, 2004.

Le condition Litteráire. La double vie des ecrivains. Paris: La Découverte, 2006.

Lichterbeck, Philipp. "Paulo Lins über seinen neuen Roman: 'Rio ist ein Sehnsuchtort für hüftsteife Europäer"'. Tagesspiegel, 07/10/2013. Disponible en $<$ http://www.tagesspiegel. de>. Acceso 14/05/2014.

Lins, Paulo. Cidade de Deus. São Paulo: Companhia das Letras, 1997. [2ª ed., 2002]

Desde que o samba é samba. São Paulo: Planeta, 2012.

"Grupos sociais são os principais personagens dos meus romances". Folha de São Paulo, 07/05/2012. <http://www1.folha.uol.com.br/> Acceso 14/05/2014.

Machado, Cassiano Eleck; Cozer, Raquel. “'Negro não é só melanina, é atitude política', diz Ferréz em Frankfurt”. Folha de São Paulo, 12/10/2013. <http://www1.folha.uol.com. br/>. Acceso 14/05/2014.

Mendes, Luiz Alberto. Memórias de um sobrevivente. São Paulo: Companhia das Letras, 2001.

Munanga, Kabengele. Rediscutindo a mestiçagem no Brasil. Identidade nacional versus. Identidade negra. Petrópolis: Vozes, 1999.

Tennina, Lucía. "Saraus das periferias de São Paulo: poesia entre tragos, silêncios e aplausos". Estudos de Literatura Brasileira Contemporânea 42 (2013): 11-28.

Nascimento, Érica Peçanha do. Vozes marginais na literatura. Rio de Janeiro: Aeroplano, 2009. "É tudo nosso! Produção cultural na periferia paulistana". Tesis doctoral en Antropología. Universidad de São Paulo, 2012

O Globo. "Paulo Lins diz que há racismo na lista da Feira de Frankfurt". O Globo, 07/10/2013.

Patrocínio, Paulo Roberto Tonani do. "Escritos à margem, a presença de autores de periferia na cena literária brasileira". Tesis doctoral en Letras. Pontifícia Universidade Católica do Rio de Janeiro, 2010.

“Allan Santos da Rosa, um outro olhar sobre a periferia”. Ipotesi 15 (2011): 57-69.

Passiani, Ennio. "Na trilha do Jeca: Monteiro Lobato, o público leitor e a formação do campo literário no Brasil". Sociologias 7 (2002): 254-270

Paiva, Marcelo Rubens. "CCidade de Deus', o livro, dá voz a quem não tem mais nada". Folha de São Paulo, 16/08/1997. <http://www1.folha.uol.com.br>. Acceso 14/05/2014.

Romero Ramos, Héctor; Santoro Domingo, Pablo. "Dos caminos en la sociología de la literatura: hacia una definición programática de la sociología de la literatura española". Revista Española de Sociología 8 (2007): 195-223

Santiago, Silviano. Vale quanto pesa. Ensaios sobre questões político-culturais. Rio de Janeiro: Paz e Terra, 1989.

Scapini, Carla Zanatta. "O documental, o testemunhal e o romanesco na narrativa autobiográfica: sobre como Luiz Alberto Mendes veio a ser”. Disertación de Maestría en Letras. Universidade Federal de Santa Maria. Santa Maria, 2010.

Schollhammer, Karl Erik. Ficção brasileira contemporânea. Rio de Janeiro: Civilização Brasileira, 2009. 
Schwarz, Roberto. "Cidade de Deus". Mais! - Folha de São Paulo, 07/09/1997. [Compilado en: Schwarz, Roberto. Seqüências brasileiras. São Paulo: Companhia das Letras, 1999. 163-171].

Silva, Mario Augusto Medeiros da. "A descoberta do insólito: Literatura Negra e Literatura Periférica no Brasil (1960-2000)”. Tesis doctoral en Sociología. Universidad Estadual de Campinas, 2011.

Silva, Simone; Tennina, Lucía. "'Literatura Marginal' de las regiones suburbanas de la Ciudad de San Pablo: el nomadismo de la voz". Ipotesi. Revista de Estudos Literarios 15/2 (2011): 13-29.

Souto, Julio. "Lecturas sociológicas de la autonomía literaria". Revista Landa 1/2 (2013): 32-56.

Souza, Jessé. "Em defesa da sociologia: o economicismo e a invisibilidade das classes sociais". Revista brasileira de sociologia 1 (2013): 129-158.

Vogt, Carlos. "Trabalho, pobreza e trabalho intelectual”. Org. Roberto Schwarz. Os pobres na literatura brasileira. São Paulo: Brasiliense, 1983.

Villarraga, Fernando Eslava. "Literatura Marginal: o assalto ao poder da escrita". Estudos de Literatura Brasileira Contemporânea 24 (2004). 